\title{
Lateralization of behavior in dairy cows in response to conspecifics and novel persons
}

\author{
C. J. C. Phillips, ${ }^{* 1}$ H. Oevermans, ${ }^{*} \dagger$ K. L. Syrett, ${ }^{*} \ddagger$ A. Y. Jespersen, ${ }^{*} \S$ and G. P. Pearce \\ ${ }^{*}$ Centre for Animal Welfare and Ethics, School of Veterinary Science, University of Queensland, Gatton 4343, QLD, Australia \\ †University for Applied Science, 8251 Dronten, the Netherlands \\ łDepartment of Veterinary Medicine, University of Cambridge, CB3 OES, United Kingdom \\ $\S$ Department of Ecology and Evolutionary Biology, Princeton University, Princeton, NJ 08544-2016
}

\begin{abstract}
The right brain hemisphere, connected to the left eye, coordinates fight and flight behaviors in a wide variety of vertebrate species. We investigated whether left eye vision predominates in dairy cows' interactions with other cows and humans, and whether dominance status affects the extent of visual lateralization. Although we found no overall lateralization of eye use to view other cows during interactions, cows that were submissive in an interaction were more likely to use their left eye to view a dominant animal. Both subordinate and older cows were more likely to use their left eye to view other cattle during interactions. Cows that predominantly used their left eye during aggressive interactions were more likely to use their left eye to view a person in unfamiliar clothing in the middle of a track by passing them on the right side. However, a person in familiar clothing was viewed predominantly with the right eye when they passed mainly on the left side. Cows predominantly using their left eyes in cow-to-cow interactions showed more overt responses to restraint in a crush compared with cows who predominantly used their right eyes during interactions (crush scores: left eye users 7.9 , right eye users 6.4 , standard error of the difference $=0.72$ ). Thus, interactions between 2 cows and between cows and people were visually lateralized, with losing and subordinate cows being more likely to use their left eyes to view winning and dominant cattle and unfamiliar humans.
\end{abstract}

Key words: dairy cow, dominance, hemispheric processing, visual lateralization

\section{INTRODUCTION}

Lateralization occurs when one hemisphere of the brain controls the cognitive processing of a specific situation and it is manifested as a contralateral side

Received July 22, 2014.

Accepted December 13, 2014

${ }^{1}$ Corresponding author: c.phillips@uq.edu.au bias, such as handedness (Rogers, 2000; Schönwiesner et al., 2007; Richter et al., 2009). Lateralization is widespread among vertebrates (Basile et al., 2009) and describes those behaviors, including motor, sensory, and cognitive responses, that are consistently biased to one side of the body at either the individual or population level (Baraud et al., 2009; Robins and Phillips, 2010; Komárková and Bartošová, 2013). It is thought that lateralization functions to facilitate multitasking through different tasks being processed in different hemispheres (Güntürkün et al., 2000; Rogers, 2000; Rogers et al., 2004; Dharmaretnam and Rogers, 2005; Ghirlanda et al., 2009) and to aid social communication and predator avoidance (Vallortigara et al., 2010). A better understanding of lateralization in cows may assist in understanding the emotions they experience and what stimuli they perceive to be threatening and stressful.

Ungulates are good candidates for highly lateralized vision, because the extremely lateralized location of their eyes allows them to scan for predators within 2 monocular fields, united in a broad field of vision of approximately $330^{\circ}$, with a blind spot only directly behind them (Piggins and Phillips, 1996). Ruminants orientate toward their object of vision by turning their head rather than their pupils (Piggins and Phillips, 1996). The high degree of decussation of bovine optic nerves in the optic chiasm (Herron et al., 1978) allows sensory cues and information coming from the left visual field to be analyzed in the right cerebral hemisphere and vice versa (Baraud et al., 2009). The right hemisphere is specialized in both perceiving and expressing emotions and serves the function of responding to unexpected stimuli, controlling escape functions, and detecting and responding to predators, especially from the left side (Robins and Phillips, 2010; Rogers, 2010; Komárková and Bartošová 2013). The left eyeright hemisphere specialization for spatial processing in novel or exploratory contexts can be related to broader vigilance functions (Robins and Phillips, 2010). Horses showing preferential left-eye use (indicating dominance 
of the right brain hemispheres) show increased fear and aggression compared with those with dominant left hemispheres (Komárková and Bartošová, 2013). The left hemisphere controls an individual's response to food items and analysis of recalled cues in cattle (Robins and Phillips, 2010), and well-established patterns of behavior performed in nonstressful situations in a wide range of species (Rogers, 2010). Left hemisphere specialization and dominance is most likely in animals not expressing fear or aggression (Komárková and Bartošová, 2013).

Cattle exhibit hierarchical organization within the herd, and the resulting dominance order may reduce aggression and stress within the herd. As stressed animals rely on predominant use of the right hemisphere (Rogers, 2010), lateralization of eye use could be an indicator of stress susceptibility. A link between dominance and another lateralized behavior, persistency of lateralized milking parlor entry, has been found previously (Prelle et al., 2004).

Some animals also display bilateral behavioral asymmetry, with behaviors involving 1 of 2 opposing limbs (e.g., initiation of walking) performed more on either the right or left side of the body, demonstrating a difference in preference or ability between the 2 sides (Annett, 1985). Such laterality may also be expressed by parts of the body extending sideways during routine behaviors; for example, tongue movement when eating. Such behavioral laterality may be related to asymmetry in body morphology. For example, diagonal symmetry of bovine hooves probably derives from asymmetrical walking or lying patterns (Phillips et al., 1996). Lateralized walking in cattle has also been demonstrated as side preferences in a T-maze (Arave et al., 1992), during entry to a milking parlor (Paranhos da Costa and Broom, 2001), and lying (Uhrbrock, 1969; Arave and Walters, 1980; Bao and Giller, 1991). Laterality may also occur because internal body parts are not symmetrical; for example, the fetus is positioned toward the right side of the body, explaining left side laterality during lying in pregnant (Wilson et al., 1999), ruminating (Albright and Arave, 1997) cows.

Cattle prefer to view a novel person in their left eye (Robins and Phillips, 2010), suggesting that they view that person as a potential predator. It is not clear whether similar visual lateralization might be present in cow-to-cow interactions, especially in the case of a subordinate cow engaged in an agonistic encounter with a dominant cow. It is conceivable that a person would be viewed by all cows as a dominant leader of the herd (Albright, 1986), whereas most cows will dominate some of their herdmates. Dominance is in part dependent on temperament (Kramer et al., 2013), and there is increasing evidence that differences in the degree of lateralization are associated with temperament in a variety of species, such as dogs (Branson and Rogers, 2006; Batt et al., 2009), horses (McGreevy and Thomson, 2006), and humans (DeYoung et al., 2010).

We hypothesized that the social context of cow-cow or cow-people interactions would influence predominant eye use, and that subordinate cows, those in losing encounters, and those showing fearful temperament traits may demonstrate greater use of their left eye than right eye during agonistic encounters with conspecifics and novel encounters with humans, as a result of signal processing in the right hemisphere of the brain. We further anticipated that the response to a human might depend on whether that person appeared familiar or not. In addition, we investigated relationships between eye use laterality and temperament, as well as productivity characteristics that may relate to priority of access to feed resources.

\section{MATERIALS AND METHODS}

The study used the dairy herd of the University of Queensland at Gatton, comprising 183 Friesian cows and 50 cows with mixed breed status, based on Friesian crosses with Jersey, Brown Swiss, and Angus. Mean milk yield, BCS (Lowman et al., 1976), and age ( \pm $\mathrm{SE})$ of cows in the herd were $25.5 \pm 0.47 \mathrm{~L} / \mathrm{d}, 3.2$ \pm 0.277 , and $4.8 \pm 0.13 \mathrm{yr}$, respectively. At $1700 \mathrm{~h}$, after p.m. milking, cows were turned out into a feedlot, where they were offered a TMR in two 60-m feed bunks (providing $52 \mathrm{~cm}$ of trough space per cow), with two 5 -m water troughs at one end of the bunks (providing $4.3 \mathrm{~cm}$ of trough space per cow), separated by a central concrete passage. At $0500 \mathrm{~h}$, cows were brought in for a.m. milking and afterward, at $0700 \mathrm{~h}$, they were sent out to pasture, from which they returned for p.m. milking at $1445 \mathrm{~h}$.

\section{Study 1: Cow Behavior in the Feedlot and Milking Parlor}

All 233 cows, identified from their ear tags, were observed engaging in agonistic interactions at the feed bunk, in the feedlot, and in the field. Preliminary observations determined that most agonistic behavior occurred after milking from 0700 to $0900 \mathrm{~h}$, and from 1130 to $1330 \mathrm{~h}$. All cows were observed by a single recorder (HO) during these times for $25 \mathrm{~d}$, spread over a 5 -wk period. During each interaction, each cow was classified as being in 1 of 6 possible positions (Figure 1). To determine the subordinate/dominant status of the cows, 3 subordinate behaviors were recorded, any one of which was assumed to indicate that cows had lost the interaction: $a=$ moved body away from other 
A:

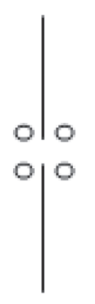

E: 이웅

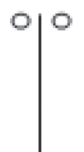

B:

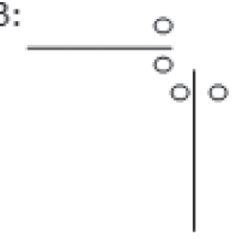

F: $0 \mid$\begin{tabular}{l|l}
0 & \\
0 & 0
\end{tabular}
C:

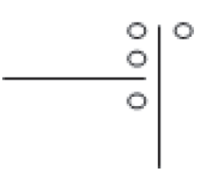

D:

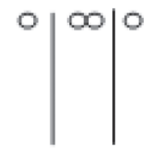

Figure 1. Diagrammatic representation of the body positions of cows during interactions. $\mathrm{A}=$ head to head, bodies at $180^{\circ} ; \mathrm{B}=$ head to head, bodies at right angles; $\mathrm{C}=$ head to side; $\mathrm{D}=$ head to head, bodies aligned; $\mathrm{E}=$ head to tail, bodies at $180^{\circ} ; \mathrm{F}=$ head to tail, bodies aligned.

animal; $b=$ moved head away from other animal, and $c$ $=$ no movement. Two dominant behaviors were recorded, either of which was assumed to indicate that the cow had won: $d=$ touched the other animal with head, or $e=$ moved head toward other animal. During each interaction it was noted which eye they predominantly used to look at the other cow during the interaction, as determined by the orientation of their face.

\section{Study 2: Forced Lateralized Movement Tests}

Observations were made of lateralization of walking down a track and possible correlations between this track behavior and visual lateralization and individual dominance values. Track walking lateralization was chosen because in the absence of any disturbance in the track, such as a person located there, cows show a normal distribution of this behavior, whereas most other behaviors demonstrate a bimodal distribution (Phillips et al., 2003). In total, 169 and 138 cows were observed in 2 studies, with individual identification by ear tags and freeze brands. Cows were observed after p.m. milking, after taking a step down from the concrete surrounding the milking parlor, walking down a 5-m-wide earth track, bordered by 2 lines of metal fencing and without any worn routes on either side (Figure 2). A novel person stood approximately $10 \mathrm{~m}$ down the track, facing the cows, thus forcing the cows to pass on the left or right side of the track. In study $2 \mathrm{~A}$, the person was dressed in familiar blue overalls, as normally worn by the veterinary students who worked regularly with the cows in this herd, whereas in study $2 \mathrm{~B}$, the person wore green overalls, a face mask, hat, and glasses to present a novel person stimulus. In study $2 \mathrm{~A}$, on alternate days, the person was either positioned on the track or not, to assess lateralization of passing a familiar person compared with a control group without the person. When no person was present on the track, cow laterality was assessed by someone hidden in an adjacent crush.

The entire herd of cows was observed for the number of right and left side passes (from the cow's perspective), indicating viewing of the person predominantly in the left and right eye fields of vision, respectively. In study $2 \mathrm{~A}$, the side on which each cow passed the person was recorded a mean of 5 times/cow on 11 individual days over a period of $21 \mathrm{~d}$, alternating daily between the person being in the crush and on the track. Scores of left or right side were awarded as the cow walked past the person, and on days that the person was absent, an additional middle score was included when no side preference was obvious. The records of 15 cows that missed some days and 47 cows that did not have prerecorded dominance values were omitted from the analysis. Side changes during passage down the track were recorded but were too rare to allow statistical analysis.

\section{Study 3: Tests of Cow Temperament}

Eight predominantly right eye-using and 8 predominantly left eye-using cows were selected from records of their interactions with other cows in study 1 (ratios 


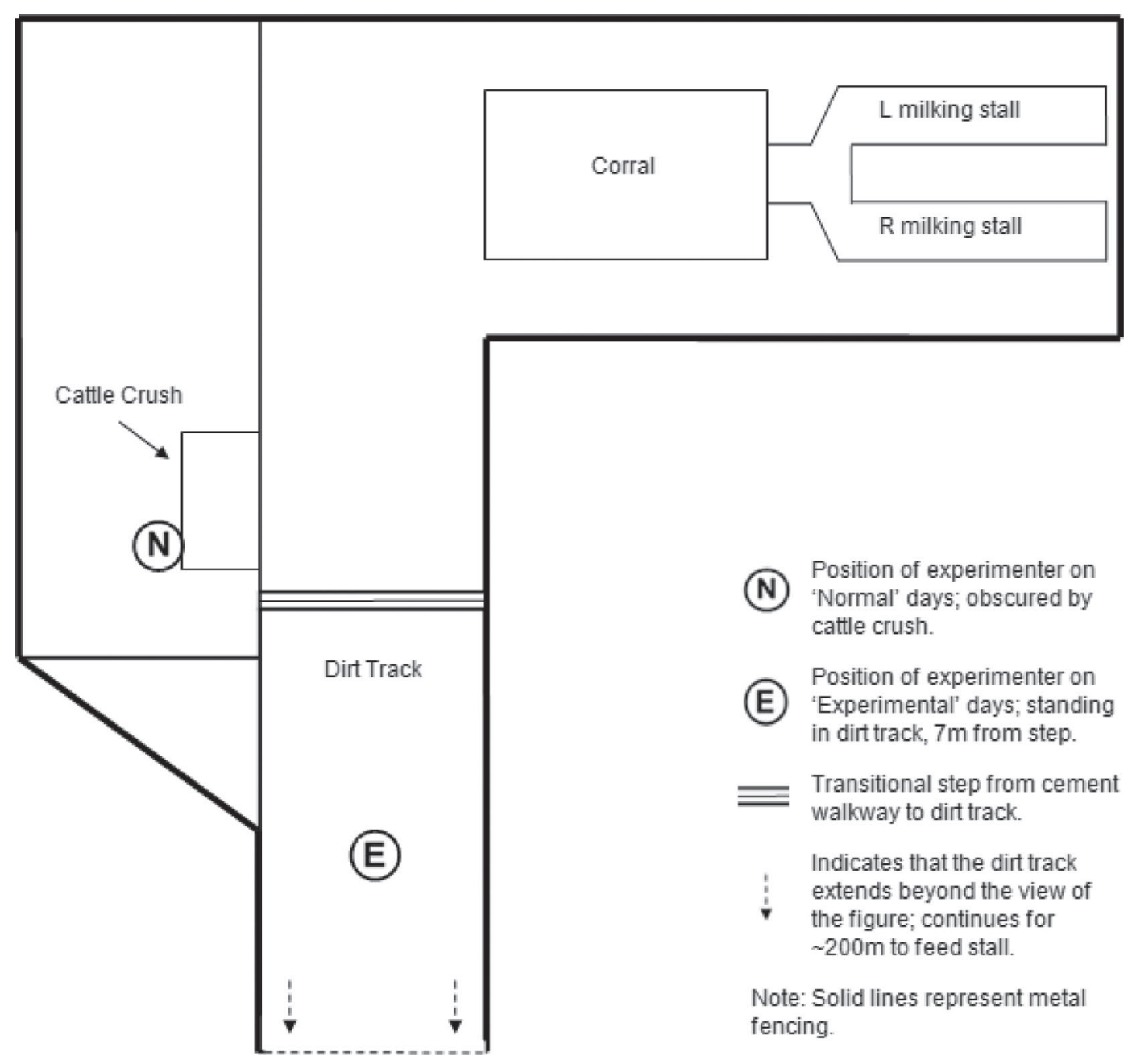

Figure 2. Milking parlor and track leading from it, in which the cows were observed.

of $<1$ and $>3$ for left:right eye use ratios, respectively, with the method of calculation detailed under Statistical Analysis below) and right and left lane use in study 2B. Temperament testing was carried out in these cows using a crush test to assess response to restraint in the presence of a human and an open field test to assess response to social isolation in a novel environment. One cow was removed from each group due to poor health and an extreme response to the crush test, which threatened the cow's welfare. Tests were carried out between 0800 and $1200 \mathrm{~h}$ and were repeated 3 times for each cow.

The crush score was used to assess the degree of restlessness of each cow, based on a categorical rating scale that assessed (1) willingness to enter the crush, (2) willingness to place their head in the head bail, (3) movement and respiration type in the crush over a 2-min period, and (4) additional scores for kicks, vocalization, kneeling, and lying attempts (Kilgour et al.,
2006). Total scores were created by summation of (1) through (4). Following exit from the crush, flight speed was recorded as the time taken for each cow to cover a distance of $2 \mathrm{~m}$, using the front feet as reference points (Petherick et al., 2002).

The open field test was used to examine cows' coping responses to physical, visual, and social isolation and a novel environment (Kilgour et al., 2006). A bare-earth collecting yard of $6 \times 9 \mathrm{~m}$ with 1.6-m-high solid sides and a nonslip floor was established at least $20 \mathrm{~m}$ from the rest of the herd. The floor of the yard was divided into 6 equal-sized squares by using spray paint. Over a 5 -min period, an observer recorded the behavior of the cattle from small slits in the solid sides, thus avoiding observer influences on cattle behaviors. The behaviors recorded were (1) number of squares entered (defined as both front feet placed in the square); (2) number of escape attempts performed, such as pushing at the sides; (3) number of vocalizations; and (4) number of 
defecations and urinations. Fecal contamination of the yard was removed between test subjects.

\section{Statistical Analysis}

Study 1. To investigate the significance of left or right eye use in winning and losing cows, the ratio of total number of times cows used their left eye $(\mathbf{L E})$ to the total number of times that they used their right eye $(\mathbf{R E})$ was calculated, with the addition of 1 to LE and $\mathrm{RE}$ data to avoid any zero-value numerators or denominators, which would give zero or infinity ratio values, respectively. The ratio for cows when they won was regressed against the ratio for cows when they lost. The dominance value of each cow was determined from the records of its interactions with other cows, using the method of Clutton-Brock et al. (1979), which incorporates information on the dominance status of animals interacted with. We chose this method over others because it is robust for large data sets with a high proportion of cows that do not interact with each other (Bang et al., 2010). The formula for calculating the dominance value (DV) of each animal was as follows:

$$
\mathrm{DV}=(\mathrm{B}+\Sigma \mathrm{b}+1) /(\mathrm{L}+\Sigma \mathrm{L}+1),
$$

where $\mathrm{B}=$ number of cows beaten; $\Sigma \mathrm{b}=$ total number of cows that the beaten cows beat, excluding the subject; $\mathrm{L}=$ number of cows that it lost to; and $\Sigma \mathrm{L}$ $=$ total number of cows that the winning cows lost to, excluding the subject.

The significance of differences in position adopted in cow-cow interactions and behavior for winners and losers was explored by Pearson's chi-squared tests. Linear regression was used to obtain further information on significant correlations, after testing for nonlinear characteristics of the fitted line and the distribution structure of the residuals by the Anderson-Darling test.

Study 2. Data were expressed as the proportion of cows walking down the left hand side of the track. In study $2 \mathrm{~A}$, d 1 data were discarded because only 23 out of 165 cows could be identified from the observation position within the crush on that day. Chi-squared analyses were used to assess the significance of deviation from an equal left and right passage.

Study 3. General linear models were constructed to investigate the differences between the selected RE and LE cows in crush score, flight speed, and the open field test, as well as mean milk yield, days in milk, lactation number, and dominance value. Residuals were tested for normal distribution using the Anderson-Darling test. Crush score and open field test total had normally distributed residuals but flight speed did not, and data distribution was not improved by transformations; therefore, a Mood's median test was used for this variable. Pearson correlation coefficients were calculated to assess the relationships between days in milk, average daily milk yield, lactation number, LE:RE ratio, left/ right ratio (from cow-to-cow interactions), crush score, flight speed, open field score, track left/right ratio, and dominance value.

The statistical package Minitab (version 16; Minitab Inc., State College, PA) was used for all calculations, with results considered significant if $P<0.05$.

\section{RESULTS}

\section{Study 1: Cow Behavior in the Feedlot and Milking Parlor}

In total, 992 interactions were recorded, and the distribution by position and behavior are shown in Table 1. Of these, 25 losing and 43 winning cows were excluded from analysis because none of the predetermined behaviors were exhibited. Twelve cows showed some head to head with bodies aligned and head to head with bodies at $180^{\circ}$ behaviors but were judged to be losers because of more extreme movements by the second cow. The most frequent position adopted was head to head with bodies aligned, followed by head to side. The most frequent behavior for losing cows was no movement, and then moving their body away, and then moving their head away. Nearly all of the behaviors of winning cows comprised a head swing toward the other animal.

Over all cows and interactions, we detected no significant difference in eye use during the interactions [mean number of times eye used/cow: LE 2.12, RE 2.12 ; standard error of the difference $($ SED $)=1.01$, $P=0.92$; Table 2]. However, we did find a significant positive relationship between the LE:RE ratio for winning cows and that for the losing cows (Figure 3):

$$
\begin{aligned}
& \text { LE:RE ratio } \text { winning cows }=0.66(\mathrm{SE} 0.0483) \\
& \quad \times \mathrm{LE}: \mathrm{RE} \text { ratio }{ }_{\text {losing cows }}(P<0.001)
\end{aligned}
$$

where LE:RE ratio is $(\mathrm{LE}+1) /(\mathrm{RE}+1)$.

This positive relationship indicates that cows that used their left eye more than their right eye when winning also did the same when losing. A coefficient of 1 would indicate that the relationship between use of left and right eyes was exactly the same for winning and losing cows. However, as the coefficient was less than unity (0.66), cows showed less extreme left eye laterality when winning than losing, indicating that there was a reduced chance that these winning cows would use 
Table 1. Recorded movements of losing (Pearson Chi-Square $=1,417, \mathrm{df}=70, P<0.001$ ) and winning cows $($ Pearson Chi-Square $=1,586, \mathrm{df}=70, P<0.001)$

\begin{tabular}{|c|c|c|c|c|c|c|}
\hline \multirow[b]{2}{*}{ Position $^{1}$} & \multicolumn{5}{|c|}{ Behavior $^{2}$} & \multirow[b]{2}{*}{ Total } \\
\hline & $a$ & $b$ & $c$ & $d$ & $e$ & \\
\hline \multicolumn{7}{|c|}{ Losing cows } \\
\hline A & 30 & 7 & 5 & 0 & 1 & 43 \\
\hline B & 12 & 1 & 5 & 0 & 0 & 18 \\
\hline $\mathrm{C}$ & 71 & 5 & 15 & 2 & 0 & 93 \\
\hline $\mathrm{D}$ & 245 & 103 & 445 & 0 & 9 & 802 \\
\hline $\mathrm{E}$ & 3 & 0 & 6 & 0 & 0 & 9 \\
\hline $\mathrm{F}$ & 1 & 0 & 0 & 0 & 0 & 1 \\
\hline Total & 362 & 116 & 476 & 2 & 10 & 966 \\
\hline \multicolumn{7}{|c|}{ Winning cows } \\
\hline A & 2 & 0 & 2 & 0 & 29 & 33 \\
\hline B & 0 & 0 & 1 & 0 & 14 & 15 \\
\hline $\mathrm{C}$ & 1 & 0 & 2 & 0 & 89 & 92 \\
\hline $\mathrm{D}$ & 10 & 0 & 19 & 0 & 770 & 799 \\
\hline $\mathrm{E}$ & 2 & 0 & 0 & 0 & 6 & 8 \\
\hline $\mathrm{F}$ & 1 & 0 & 0 & 0 & 0 & 1 \\
\hline Total & 16 & 0 & 24 & 0 & 908 & 948 \\
\hline
\end{tabular}

${ }^{1}$ Position codes: $\mathrm{A}=$ head to head, bodies at $180^{\circ}: \mathrm{B}=$ head to head, bodies at right angles; $\mathrm{C}=$ head to side; $\mathrm{D}=$ head to head, bodies aligned; $\mathrm{E}=$ head to tail, bodies at $180^{\circ} ; \mathrm{F}=$ head to tail, bodies aligned.

${ }^{2}$ Behavior codes: $a=$ moved body away from other animal; $b=$ moved head away from other animal, or $c=$ no movement; $d=$ touched the other animal with head, and $e=$ moved head toward other animal

their left eye than losing cows. We detected a tendency for a higher ratio of left to right eye use when the cows demonstrated behavior $c$ (no movement) than when cows demonstrated behavior $a$ or $b$ (moving their body or head away; LE:RE means $a 1.14 ; b 1.13 ; c 1.25$; SED $=0.0634, P=0.10$ ).

Dominance values were not normally distributed (Anderson-Darling test, $P<0.005$ ), but $\log _{10}$-transformed DV values (dv) were (Anderson Darling test, $P=0.27$; Figure 4$)$. There was a negative relationship $(P=0.01)$ between the ratio of left eye to right eye use in the losing cows and $\log _{10}$ transformed dominance values $(\mathrm{dv})$ :

$$
\mathrm{LE}: \mathrm{RE} \text { ratio }_{\text {losing cows }}=-0.39( \pm 0.148) \log _{10} \mathrm{dv} .
$$

Hence, the more dominant a losing cow was, the greater the likelihood that she would use her right eye in interactions. Similarly, in the winning cows, we observed a negative relationship $(P=0.01)$ between the ratio of left eye to right eye use and transformed dominance values $(\mathrm{dv})$, indicating that the more dominant that winning cows were, the more likely they were to use their right eye:

$$
\text { LE:RE ratio } \text { winning cows }=-0.38( \pm 0.147) \log _{10} \mathrm{dv} \text {. }
$$

Hence, dominance is more influential than winning or losing in determining eye use. We found a positive correlation between dominance value and age of the cows (Spearman rank correlation coefficient $=0.39, P$ $<0.001)$ and a positive relationship between age and the ratio of left eye use to right eye use in both losing and winning cows:

$$
\begin{aligned}
& \text { Losing cows: } \mathrm{LE}: \mathrm{RE} \text { ratio }_{\text {losing cows }}=6.4 \times 10^{-3} \\
& \left( \pm 3.46 \times 10^{-3}\right) \text { age }(P<0.001)
\end{aligned}
$$

Winning cows: LE:RE ratio winning cows $=$

$$
6.1 \times 10^{-3}\left( \pm 3.84 \times 10^{-3}\right) \text { age }(P<0.001) \text {. }
$$

Table 2. The ratio of left to right eye use (with addition of 1 ) for losers and winners in aggressive interactions

\begin{tabular}{lccccc}
\hline Variable & Mean & SEM & Minimum & Median & Maximum \\
\hline Left loser & 2.15 & 0.124 & 0 & 2 & 10 \\
Right loser & 2.10 & 0.126 & 0 & 2 & 13 \\
Left winner & 2.10 & 0.163 & 0 & 1 & 11 \\
Right winner & 2.14 & 0.171 & 0 & 1 & 17 \\
\hline
\end{tabular}




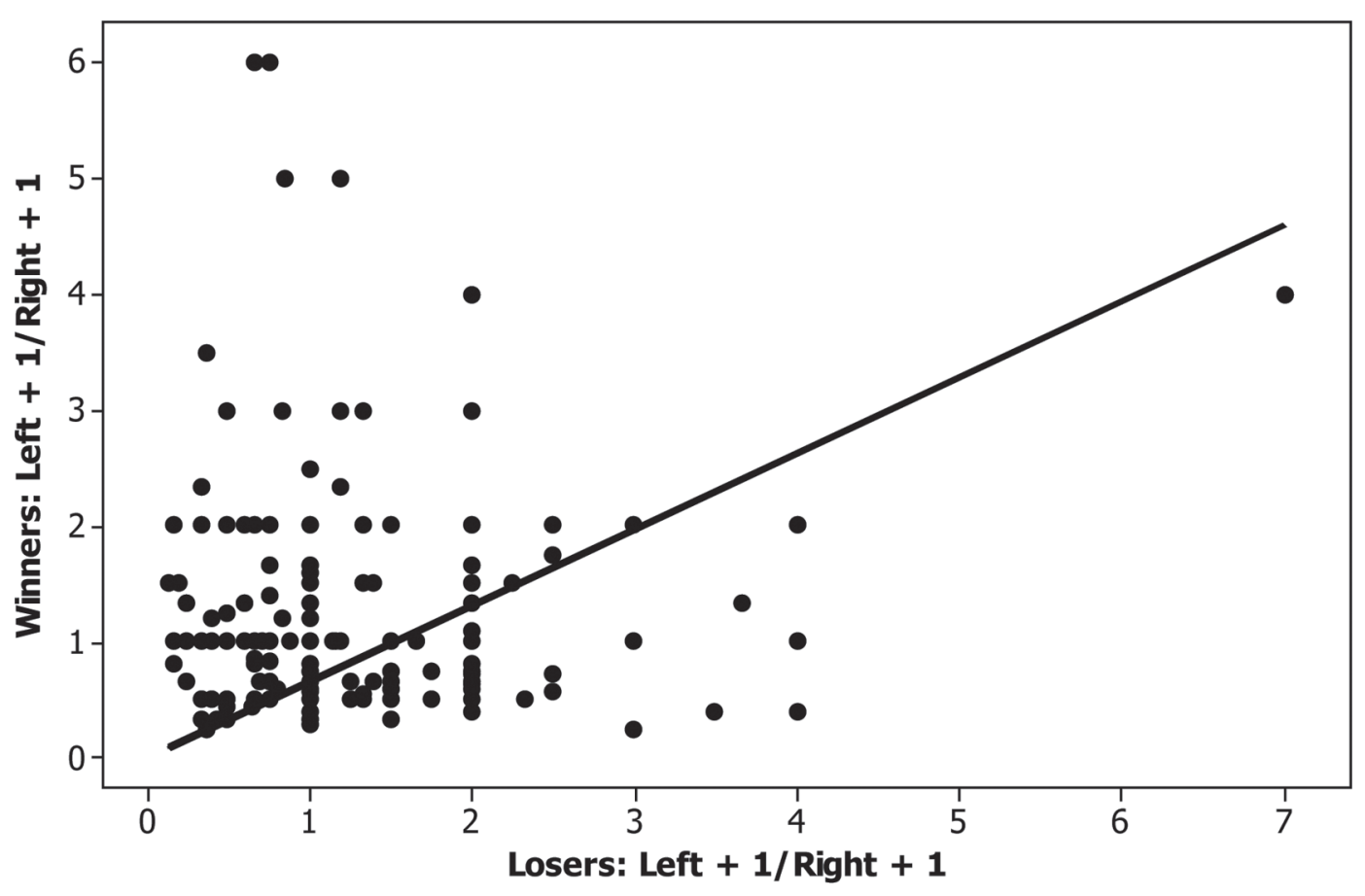

Figure 3. Relationship between winners and losers in their ratio of left to right eye use.

Thus, both winning and losing cows were more likely to use their left eye as they aged. We also detected a positive relationship between BCS and use of the right eye by winning cows (Spearman rank correlation coefficient $=0.15, P=0.05)$.

\section{Study 2: Forced Lateralized Movement Tests}

Study 2A: Experimenter in Familiar Clothing. In the first set of measurements of cow track walking behavior, $14.7 \%$ of the cows took a middle path, which was consistent over time; therefore, results are presented only for cows going left or right. The majority, 70 to $90 \%$, of the cows initially walked down the left side viewing the experimenter in their right eye when the experimenter in familiar clothing was present, and they maintained this for the remainder of the measurements, except for measurements on d 18 (Figure 5). When the experimenter was present in the crush, the majority of cows $(84 \%)$ walked down the right side initially but, over the next $4 \mathrm{~d}$, this progressively changed to the left side, until over $90 \%$ walked down the left side.

Study 2B: Experimenter in Unfamiliar Clothing. When the experimenter wore unfamiliar clothing, a mask, and hat and stood in the center of the track, most cows walked to the right of the track, viewing the experimenter in their left eye, on the first day $\left(\chi^{2}\right.$ $=29.7, P=0.01$; Figure 6 ). After this, they walked down both sides equally, except that on $\mathrm{d} 3$ and 9 cows again walked to more to the right side $\left(\chi^{2}=17.5\right.$ and 5.5, respectively, $P=0.05)$, which appeared to be as a result of disturbances during milking on that day.

The histogram of left- and right-side passage down the track shows a bimodal pattern, with most cows walking consistently down the left or the right side of the experimenter over the $14 \mathrm{~d}$ (Figure 7). We observed an increase in right:left side ratio of passage down the track for LE cows compared with RE cows $\left[\log _{10}\right.$ values: LE 0.85, RE -0.82 (antilog 7.1, 0.15, respectively); SED $0.156, P<0.01]$. Supporting this, there was a positive correlation between LE:RE ratio in the between-cow confrontations and the left to right side ratio in study 2B $(\mathrm{r}=0.68, P<0.01)$.

\section{Study 3: Tests of Cow Temperament}

The LE cows had greater total crush scores than the RE cows (LE 7.9, RE 6.4; SED $=0.72, P=0.01$ ), and the crush score was correlated with DV $(\mathrm{r}=0.67, P=$ $0.009)$. We found no difference in total open field test scores for LE and RE cows (LE 20.3, RE 16.0; SED = 5.88, $P=0.41$ ), but the open field test score and DV were correlated (CC $0.68, P=0.001$ ) and we found a tendency for crush score to be correlated with open field test score (CC 0.48, $P=0.068)$. Crush score was negatively correlated with LE:RE ratio $(\mathrm{CC}-0.67, P$ $=0.02)$ and correlated with left to right side ratio in study $2 \mathrm{~B}(\mathrm{r}=0.59, P=0.02)$. 


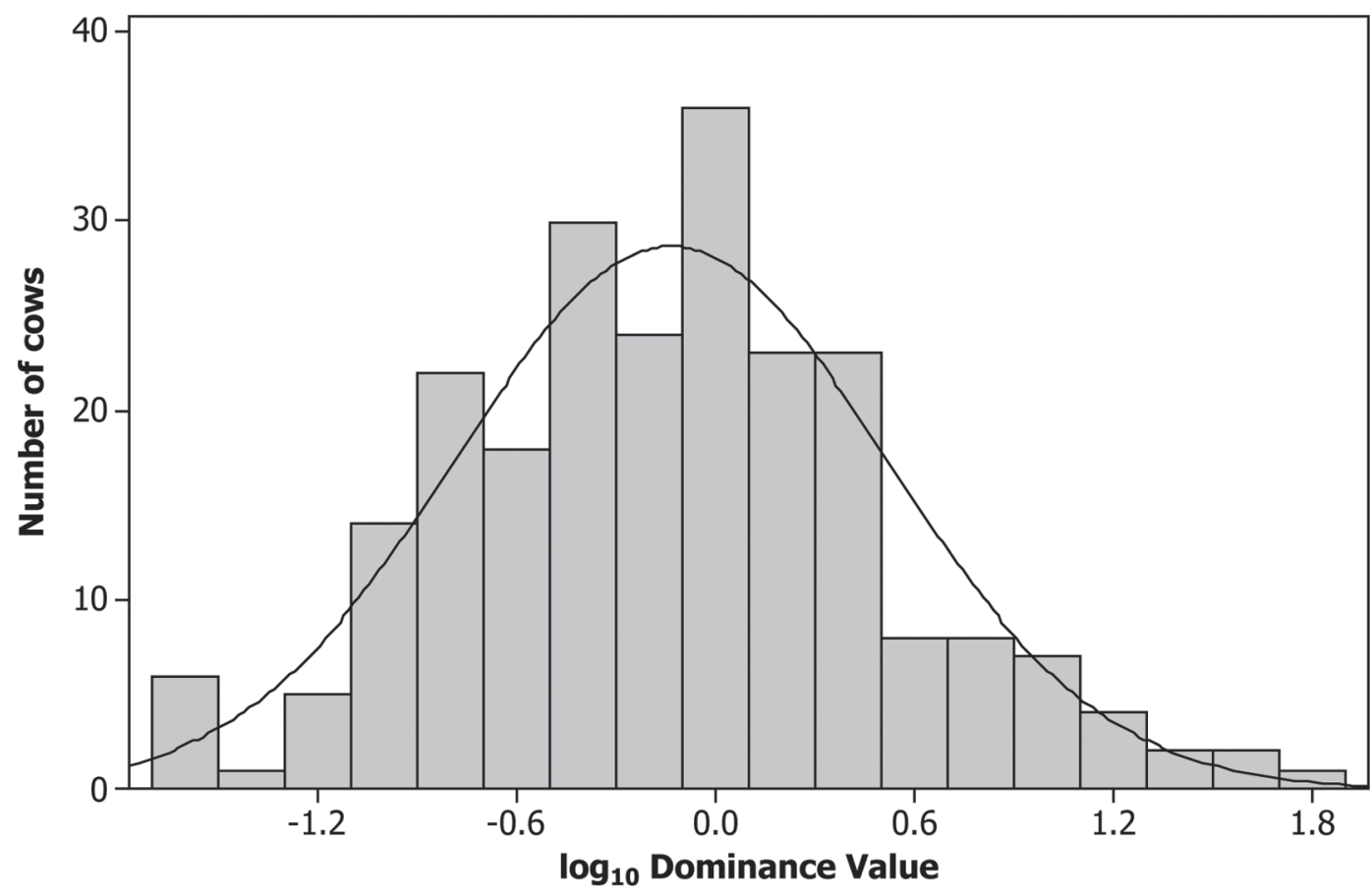

Figure 4. Distribution of $\log _{10}$ dominance values, with normal distribution curve.

We observed no significant differences in individual components of the scores, except for a significant increase in escape score of LE cows in the open field test (squared values: LE 31.5, RE 8.8; $\mathrm{SED}=24.69, P=$ $0.03)$. However, residuals were not normally distributed $(P<0.005)$ and some caution is warranted. We de-

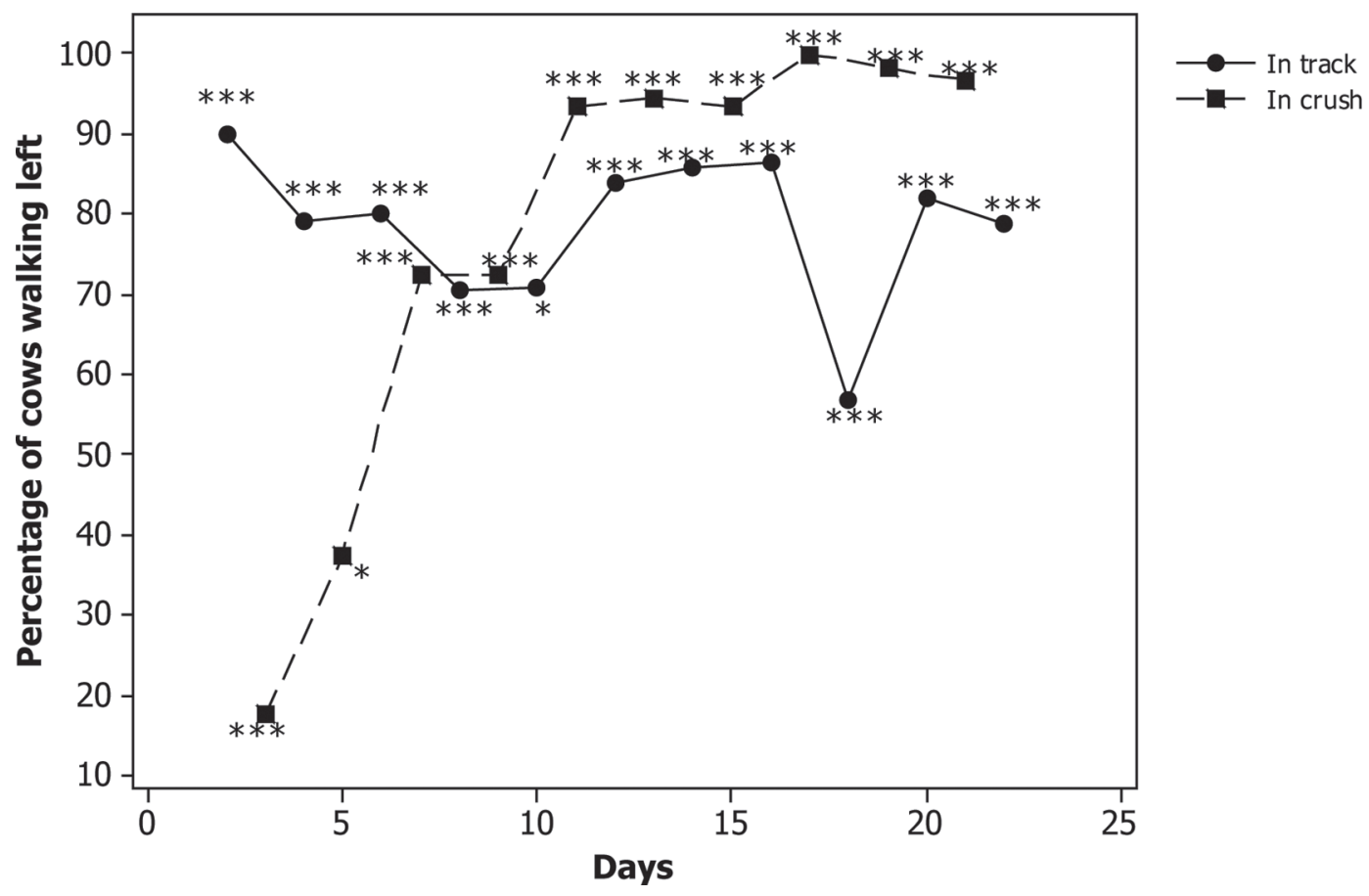

Figure 5. Percentage of cows walking down the left side of the track with the experimenter in familiar clothing either in the track or in the crush $(* P \leq 0.05 ; * * * P \leq 0.001)$. 


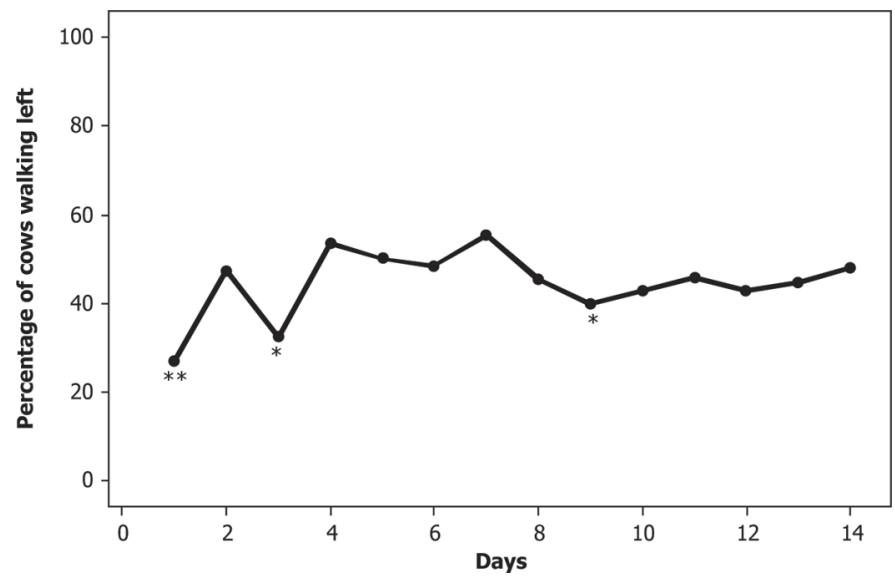

Figure 6. Percentage of cows walking down the left side of the track with the experimenter in unfamiliar clothing and wearing a mask in the track $\left({ }^{*} P \leq 0.05\right)$.

tected no significant difference in flight speed between eye groups (LE $0.47, \mathrm{RE} 0.49 ; P=0.98$ ).

\section{DISCUSSION}

\section{Study 1: Cow Behavior in the Feedlot and Milking Parlor}

The results of this study demonstrate that the contest-losing cows and subordinate cows were more likely to use their left eye in encounters, suggesting that their flight-or-fight response was heightened. We accept that an element of chance may have been involved in the orientation of the 2 cows, especially in the more crowded locations, such as the milking parlor. However, this is not likely to have introduced any systematic bias into the measurements, but could have increased the random variation in orientation measurements, which we overcame with relatively large numbers of animals for the study.

In conditions of restricted resources, social hierarchy functions to limit aggression. Despite this, in dairy cow systems, subordinate dairy cows are the subject of regular aggression from dominant cows (Castro et al., 2011), causing them to experience more stress during encounters. In this study, we recorded approximately 10 interactions per hour of study, or 0.04 interactions per cow per hour, demonstrating relatively high rates of aggression. There is limited evidence that subordinate cows are more nervous than dominant cows, with lower productivity levels and potentially less efficient digestive behavior (Reinhardt, 1973; Phillips and Rind, 2002). They are willing to sacrifice food quality to avoid contact with dominant cattle (Rioja-Lang et al., 2012), and the positive association of BCS with right eye use in the present study supports this. We investigated BCS as a potentially useful proxy measure for dominance, knowing that there was potential for error surrounding

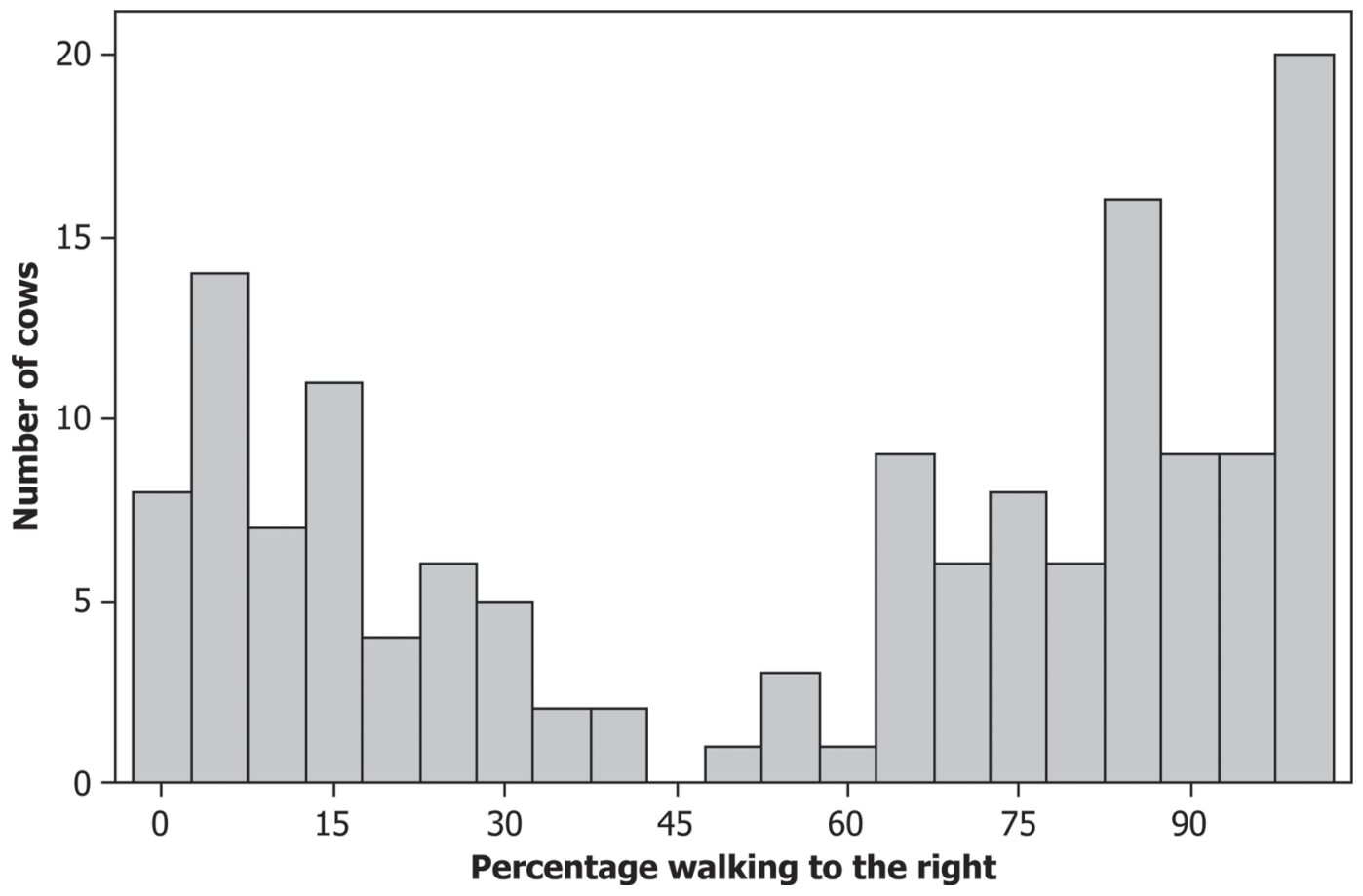

Figure 7. Proportion of cows $(\mathrm{n}=148)$ walking to the left side of the experimenter over $14 \mathrm{~d}$. 
the measurement of the latter because of the large number of cow-cow interactions that need to be measured. However, the statistical evidence for relations between eye use and dominance was actually stronger than that between dominance and BCS, which suggests that our measurement of dominance was robust.

At a physiological level, androgen treatment of cattle enhances their dominance and reduces fearfulness (Boissy and Bouissou, 1994). The relationship between social dominance of cattle and their temperament is therefore complex and probably context specific. One study with beef cattle has suggested that middle-ranking cattle have the least stress (Miranda-de la Lama et al., 2013), but others found no relationship (Partida et al., 2007). Lateralization of parlor entry has, however, been detected more in dominant cows than in subordinate cows (Prelle et al., 2004). Studies are needed in dairy cows to relate social dominance to temperament and stress-related behavior.

\section{Study 2: Forced Lateralized Movement Tests}

Cows appeared to initially respond differently to the person in familiar clothing and unfamiliar clothing. Familiar clothing led to left side passage and viewing the person in their right eye, which was consistent over time, whereas on the first day the unfamiliar person was largely passed down the right side, viewing the person on their left side. This agrees with research by Robins and Phillips (2010), in which the first passage across a novel person's path when bisecting the herd was predominantly from right to left, viewing the person in their left eye, and the second passage bisecting the herd after it had settled was in the opposite direction, viewing the person in their right eye. The response to the person in the crush, initially to the right and then increasingly to the left over time, may indicate an initial desire to investigate the person in the crush, followed by avoidance by switching to the left-hand side. Such a transition would only be possible if the person's presence could be detected at a distance, which is possible from odor cues.

We found a strong correlation between ratio of left to right eye use in the cow-to-cow confrontations and the left to right ratio in the track study; this indicates that cows consistently had a preferred eye to view all interactions they encounter. Cows clearly had a preferred eye to view novel stimuli (person in track) and they were relatively consistent in how they viewed this stimulus.

\section{Study 3: Tests of Cow Temperament}

Cows that predominantly used their left eye in cowto-cow interactions and cow-to-human interactions had higher total crush scores. A greater crush score describes an animal with a restless disposition when a person is present, and the link to left eye use provides further evidence of a heightened flight-or-fight response in these cows (Robins and Phillips, 2010). We also found a correlation between crush and open field scores, which was to be expected, as they are both measures of activity responses to a stressful situation. The absence of any difference between predominantly $\mathrm{RE}$ and LE cows in the open field test may be due to a variety of factors. One is the small sample size in this study and, although the number of escape attempts was significantly greater in LE cows, the residuals were not normally distributed. A larger sample size might have overcome this problem. The open field test is a test commonly used for dairy cows, with movement, vocalizations, time spent immobile, and exploration time being the most repeatable measurements (Forkman et al., 2007). However, there is concern about which emotions it measures: in heifers, locomotion is more related to activity than fear of novelty (Boissy and Boissou, 1995), and in calves, it is more related to social isolation (de Passillé and Martin, 1995). As our cows were group-reared, it is likely that social isolation was the greatest factor affecting scores in the open field test (Munksgaard and Simonsen, 1996). Inactivity could indicate a settled nature but alternatively might suggest that the cow is stressed by separation from conspecifics (Boissy and Boissou, 1995), making interpretation of the test results difficult. As a test of fear responses, the open field test correlates to some degree with behavior seen in other fear tests (Boissy and Boissou, 1995; Kilgour et al., 2006), but the correlations are not strong (Forkman et al., 2007); hence, we used it in combination with other tests.

This study found that DV was positively correlated with crush and open field scores. This suggests that dominant cows are more disturbed by the presence of a person (crush score) and novel environment (open field test) than subordinate cows, whereas their increased use of the right eye in interactions with other cows suggests that they are less fearful in the presence of conspecifics. This is expected because the DV was measured from interactions with other cows in study 1 . In that study, we found no correlation between LE:RE and DV; however, in study 1, dominant cows were more likely to use their right eye in interactions with losing cows, showing that their response to fearful stimuli was less aroused than in subordinate cows.

\section{CONCLUSIONS}

Losing and subordinate cows were more likely to use their left than right eye to view other cows during 
interactions. This suggests a heightened flight-or-fight response. The forced lateralization test described appears to be a suitable test to explore the emotional responses of cattle to novel stimuli. Cows that predominantly used their left eye in all types of interactions had a more fearful temperament, as indicated by heightened responses to confinement in the crush, indicating that these individuals perceived this as more stressful. We conclude that the eye that dairy cows use in interactions with other cattle and humans can provide valuable information on their temperament.

\section{ACKNOWLEDGMENTS}

The authors thank Christlijke Agarische Hogeschule (Dronten, the Netherlands) for support of H. Oevermans, and the University Federation for Animal Welfare (Potters Bar, UK), Stephen Hale Bursary, and Corpus Christi College, University of Cambridge, for support for K. L. Syrett. Phil Martin of the University of Queensland and his dairy herd staff gave invaluable assistance.

\section{REFERENCES}

Albright, J. L. 1986. Human/farm animal relationships. Pages 51-66 in Advances in Animal Welfare Science. M. W. Fox and L. D. Mickley, ed. The Humane Society of the United States, Washington, DC.

Albright, J. L., and C. W. Arave. 1997. The Behavior of Cattle. CAB International, Wallingford, UK.

Annett, M. 1985. Left, Right, Hand and Brain: The Right Shift Theory. A. Wheaton and Co. Ltd., Exeter, UK.

Arave, C. W., R. C. Lamb, M. J. Arambel, D. Purcell, and J. L. Walters. 1992. Behavior and maze learning ability of dairy calves as influenced by housing, sex and sire. Appl. Anim. Behav. Sci. 33:149-163.

Arave, C. W., and J. L. Walters. 1980. Factors affecting lying behavior and stall utilization of dairy cattle. Appl. Anim. Ethol. 6:369-376.

Bang, A., S. Deshpande, A. Sumana, and R. Gadagkar. 2010. Choosing an appropriate index to construct dominance hierarchies in animal societies: A comparison of three indices. Anim. Behav. 79:631-636.

Bao, J., and P. S. Giller. 1991. Observations on the changes in behavioral activities of dairy cows prior to and after parturition. Irish Vet. $44: 43-47$.

Baraud, I., B. Buytet, P. Bec, and C. Blois-Heulin. 2009. Social laterality and 'transversality' in two species of mangabeys: Influence of rank and implication for hemispheric specialization. Behav. Brain Res. 198:449-458.

Basile, M., S. Boivin, and A. Boutin. 2009. Socially dependent auditory laterality in domestic horses. Anim. Cogn. 12:611-619.

Batt, L. S., M. S. Batt, J. A. Baguley, and P. D. McGreevy. 2009. The relationships between motor lateralization, salivary cortisol concentrations and behavior in dogs. J. Vet. Behav. 4:216-222.

Boissy, A., and M. F. Bouissou. 1994. Effects of androgen treatment on behavioural and physiological responses of heifers to fear-eliciting situations. Horm. Behav. 28:66-83.

Boissy, A., and M. F. Bouissou. 1995. Assessment of individual differences in behavioural reactions of heifers exposed to various feareliciting situations. Appl. Anim. Behav. Sci. 46:17-31.
Branson, N. J., and L. J. Rogers. 2006. Relationship between paw preference strength and noise phobia in Canis familiaris. J. Comp. Psychol. 120:176-183.

Castro, I. M., L. Gygax, B. Wechsler, and R. Hauser. 2011. Increasing the interval between winter outdoor exercise aggravates agonistic interactions in Herens cows kept in tie-stalls. Appl. Anim. Behav. Sci. 129:59-66.

Clutton-Brock, T. H., S. D. Albon, R. M. Gibson, and F. E. Guinness. 1979. The logical stag: adaptive aspects of fighting in red deer (Cervus elaphus). Anim. Behav. 27:211-225.

de Passillé, J. R., and F. Martin. 1995. Interpreting the behaviour of calves in an open-field test: A factor analysis. Appl. Anim. Behav. Sci. 45:201-213.

DeYoung, C. G., J. B. Hirsh, M. S. Shane, X. Papademetris, N. Rajeevan, and J. R. Gray. 2010. Testing predictions from personality neuroscience. Brain structure and the big five. Psychol. Sci. $21: 820-828$.

Dharmaretnam, M., and L. J. Rogers. 2005. Hemispheric specialization and dual processing in strongly versus weakly lateralized chicks. Behav. Brain Res. 162:62-70.

Forkman, B., A. Boissy, and M. C. Meunier-Salauen. 2007. A critical review of fear tests used on cattle, pigs, sheep, poultry and horses. Physiol. Behav. 92:340-374.

Ghirlanda, S., E. Frasnelli, and G. Vallortigara. 2009. Intraspecific competition and coordination in the evolution of lateralization. Philos. Trans. R. Soc. Lond. B Biol. Sci. 364:861-866.

Güntürkün, O., B. Diekamp, M. Manns, F. Nottelmann, H. Prior, A. Schwarz, and M. Skiba. 2000. Asymmetry pays: Visual lateralization visual lateralization improves discrimination success in pigeons. Curr. Biol. 10:1079-1081.

Herron, M. A., J. E. Martin, and J. R. Joyce. 1978. Quantitative study of the decussating optic axons in the pony, cow, sheep, and pig. Am. J. Vet. Res. 39:1137-1139.

Kilgour, R. J., G. J. U. Melville, and P. L. Greenwoold. 2006. Individual differences in the reaction of beef cattle to situations involving social isolation, close proximity of humans, restraint and novelty. Appl. Anim. Behav. Sci. 99:21-40.

Komárková, M., and J. Bartošová. 2013. Lateralized suckling in domestic horses. Anim. Cogn. 16:343-349.

Kramer, M., M. Erbe, B. Bapst, A. Bieber, and H. Simianer. 2013. Estimation of genetic parameters for novel functional traits in Brown Swiss cattle. J. Dairy Sci. 96:5954-5964.

Lowman, B. G., N. A. Scott, and S. H. Somerville. 1976. Condition Scoring of Cattle. East of Scotland College of Agriculture (ESCA) Bulletin 6. ESCA, Edinburgh, UK.

McGreevy, P. D., and P. C. Thomson. 2006. Differences in motor laterality between breeds of performance horse Paul D. Appl. Anim. Behav. Sci. 99:183-190.

Miranda-de la Lama, G. C., M. Pascual-Alonso, A. Guerrero, P. Alberti, S. Alierta, P. Sans, J. P. Gajan, M. Villarroel, A. Dalmau, and A. M. M. Velarde. 2013. Influence of social dominance on production, welfare and the quality of meat from beef bulls. Meat Sci. 94:432-437.

Munksgaard, L., and H. B. Simonsen. 1996. Behavioral and pituitary adrenal-axis responses of dairy cows to social isolation and deprivation of lying down. J. Anim. Sci. 74:769-778.

Paranhos da Costa, M. J. R., and D. M. Broom. 2001. Consistency of side choice in the milking parlour by Holstein/Friesian cows and its relationship with their reactivity and milk yield. Appl. Anim. Behav. Sci. 70:177-186.

Partida, J. A., J. L. Olleta, and M. M. Campo. 2007. Effect of social dominance on the meat quality of young Friesian bulls. Meat Sci. $76: 266-273$.

Petherick, J. C., R. G. Holroyd, V. Doogan, and B. K. Venus. 2002. Productivity, carcass and meat quality of lot-fed Bos indicus cross steers grouped according to temperament. Aust. J. Exp. Agric. 42:389-398.

Phillips, C. J. C., S. Llewellyn, and A. Claudia. 2003. Laterality in bovine behavior in an extensive partially suckled herd and an intensive dairy herd. J. Dairy Sci. 86:3167-3173. 
Phillips, C. J. C., S. J. Patterson, I. Ap Dewi, and C. J. Whittaker. 1996. Volume assessment of the bovine hoof. Res. Vet. Sci. $61: 125-128$.

Phillips, C. J. C., and M. I. Rind. 2002. The effects of social dominance on the production and behaviour of grazing dairy cows offered forage supplements. J. Dairy Sci. 85:51-59.

Piggins, D., and C. J. C. Phillips. 1996. The eye of the domesticated sheep with implications for vision. Anim. Sci. 62:301-308.

Prelle, I., C. J. C. Phillips, M. J. Paranhos da Costa, N. C. Vandenberghe, and D. M. Broom. 2004. Are cows that consistently enter the same side of a two-sided milking parlor more fearful of novel situations or more competitive? Appl. Anim. Behav. Sci. 87:193-203.

Reinhardt, V. 1973. Social rank order and milking order in cows. Z Tierpsychol. 32:281-292.

Richter, N., E. Schröger, and R. Rübsamen. 2009. Hemispheric specialization during discrimination of sound sources reflected by MMN Neuropsychologia 47:2652-2659.

Rioja-Lang, F. C., D. J. Roberts, S. D. Healy, A. B. Lawrence, and M. J. Haskell. 2012. Dairy cow feeding space requirements assessed in a Y-maze choice test. J. Dairy Sci. 95:3954-3960.

Robins, A., and C. J. C. Phillips. 2010. Lateralized visual processing in domestic cattle herds responding to novel and familiar stressors. Lateral. Asymm. Body Brain Cogn. 15:514-534.
Rogers, L. J. 2000. Evolution of hemispheric specialisation: Advantages and disadvantages. Brain Lang. 73:236-253.

Rogers, L. J. 2010. Relevance of brain and behavioural lateralization to animal welfare. Appl. Anim. Behav. Sci. 127:1-11.

Rogers, L. J., P. Zucca, and G. Vallortigara. 2004. Advantages of having a lateralized brain. Proc. Biol. Sci. 271:S420-S422.

Schönwiesner, M., K. Krumbholz, R. Rübsamen, G. R. Fink, and D. Y. von Cramon. 2007. Hemispheric asymmetry for auditory processing in the human auditory brain stem, thalamus, and cortex. Cereb. Cortex 17:492-499.

Uhrbrock, R. S. 1969. Bovine laterality. J. Genet. Psychol. 115:77-79.

Vallortigara, G., C. Chiandetti, R. Rugani, V. A. Sovrano, and L. Regolin. 2010. Animal cognition. Wiley Interdisc. Rev. Cogn. Sci. 1:882-893.

Wilson, L. L., L. Terosky, C. L. Stull, and W. R. Stricklin. 1999. Effects of individual housing design and size on behavior and stress indicators of special-fed Holstein veal calves. J. Anim. Sci. $77: 1341-1347$ 